\title{
The extreme northern jet of the Antarctic Circumpolar Current
}

\author{
E. G. Morozov ${ }^{1}$, D. I. Frey ${ }^{1}$, D. V. Fofanov ${ }^{1}$, V. A. Krechik ${ }^{1}$, R. Yu. Tarakanov ${ }^{1}$, and \\ D. L. Vinokurov ${ }^{1}$
}

Received 26 April 2020; accepted 19 May 2020; published 28 August 2020.

We analyze the location of the extreme northern jet of the Antarctic Circumpolar Current based on the measurements in cruise 79 of the $\mathrm{R} / \mathrm{V}$ Akademik Mstislav Keldysh to the region of the Drake Passage in February-March 2020. The jet occupies a position over the slope of Tierra del Fuego Island over a depth range of 400-600 $\mathrm{m}$ based on the measurements along four sections using the shipborne SADCP and CTD/LADCP casts. The width of this coastal jet is about $15-20 \mathrm{~km}$. It penetrates to the depths of 200-300 m. The jet follows the direction of isobaths. Velocities in the jet reach $40 \mathrm{~cm} / \mathrm{s}$. It is likely that this jet is a local one and does not continue along the entire circle around Antarctica, but based on the satellite data of the absolute dynamical topography (ADT) this jet continues into the shallow region between Tierra del Fuego and Falkland Islands. KEYWORDS: Antarctic Circumpolar Current; northern jet; CTD measurements; shipborne ADCP; Drake Passage.

Citation: Morozov, E. G., D. I. Frey, D. V. Fofanov, V. A. Krechik, R. Yu. Tarakanov, and D. L. Vinokurov (2020), The extreme northern jet of the Antarctic Circumpolar Current, Russ. J. Earth. Sci., 20, ES5004, doi:10.2205/2020ES000717.

\section{Introduction}

Antarctic Circumpolar Current (ACC) in the Drake Passage is limited by the continental slopes of Tierra del Fuego and Antarctica. This geostrophic current is intensified by strong western winds and spreads to a depth of up to $2500 \mathrm{~m}$ [Koshlyakov et al., 2013, Tarakanov, 2012]. In the northern periphery of the ACC the current spreads not deeper that 1000-1500 m [Tarakanov, 2012]. The ACC has an equivalent-barotropic structure [Killworth and Hughes, 2002], i.e. the pattern of streamlines in the deep layers is similar to that at the ocean surface. Numerous publications report that the ACC is formed of several jets related to the dynamical fronts [Berloff, 2009, Tarakanov and Gritsenko, 2018. It follows from the physical

\footnotetext{
${ }^{1}$ Shirshov Institute of Oceanology RAS, Moscow, Russia
}

Copyright 2020 by the Geophysical Center RAS. http://rjes.wdcb.ru/doi/2020ES000717-res.html structure of the geostrophic currents that dynamical fronts correspond to the zones of increased horizontal gradients of temperature and salinity; hence, the density gradients are also high [Deacon, 1937 . Tarakanov and Gritsenko, 2018.

Before [Kort, 1959] the researchers distinguished only two ACC jets associated with the Subantarctic (SAF) and Polar (PF) fronts. These jets were related to the hydrological fronts. The scholars of previous years used the terms of Antarctic divergence and convergence. Burkov 1994 was the first who noticed the existence of additional ACC jets based on the analysis of hydrographic sections in Antarctica available at that time. One year later, the authors of [Orsi et al., 1995] distinguished three ACC jets also on the basis of the data of hydrographic sections. In addition to the Polar and Subantarctic fronts, they distinguished the Southern ACC Front (SACCF). Three-jet structure of the ACC by [Orsi et al., 1995 is currently considered classical. 

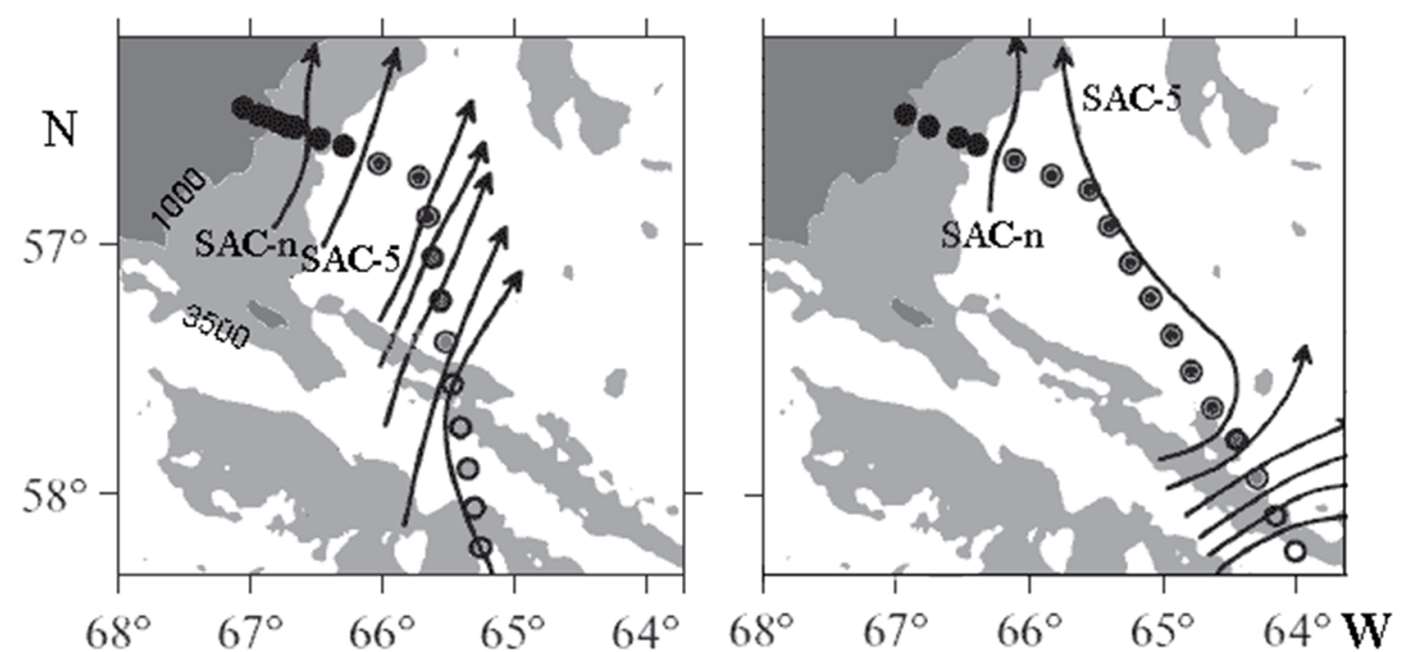

Figure 1. Schemes of ACC jets in the upper ocean layer in the northern part of the Drake Passage in 2010 (left) and 2011 (right). The dark gray and light gray colors show the regions with depths shallower than 1000 and $3500 \mathrm{~m}$, respectively. The circles indicate CTD/LADCP stations. Adopted and modified from [Tarakanov and Gritsenko, 2018 .

According to the terminology given in [Koshlyakov et al., 2011, dynamical fronts should be called currents, but not fronts. Term "front" is related to hydrological fronts, i.e. the fronts limiting spreading of water masses. Thus, dynamical Subantarctic Front becomes the Subantarctic Current (SAC), the Polar Front becomes the Southern Polar Current (SPC), and the South ACC Front becomes the Southern Antarctic Current (SthAC).

Sokolov and Rintoul 2009 analyzed the satellite altimetry data and suggested distinguishing nine ACC jets, which are continuous in the entire circumpolar region. Tarakanov and Gritsenko 2014a, 2014b distinguished 12 simultaneously existing ACC jets south of Africa on the basis of satellite altimetry data. During a period up to six months these jets were stably confined to the same ranges of dynamical topography. Contour lines of this topography correspond to the streamlines of the geostrophic currents at the ocean surface. In particular, they distinguished six jets in the zone of the Subantarctic Current. These are SAC-s, SAC2, SAV-3, SAC-m, SAC-5, and SAC-n. These jets are numbered from 1 to 6 but some of the numbers are substituted by indices "s", "m", and "n", which correspond to the southern, middle, and northern jets. The SAC-m corresponds to the classical hydrological front SAF. Later, Tarakanov and Gritsenko 2018 studied the jet structure of the ACC over two lines across the Drake Passage in the context of the 12-jet ACC structure that they suggested. These two sections were occupied in different years and their tracks were different. They showed that less than 12 individual jets are distinguished, which means that there are less than 12 segments of the section, which are characterized by a local longitudinal velocity maximum. These individual jets are different combinations of merged jets from the 12-jet ACC structure. However, nine-jet structure suggested by Sokolov and Rintoul 2009 is not sufficient for the description of the structure of individual ACC jets.

All the jets of the Subantarctic Current based on the analysis in [Tarakanov and Gritsenko, 2018] are located in the latitudinal range from $57^{\circ} 20^{\prime} \mathrm{S}$ to the coasts of Tierra del Fuego. The northernmost jet among them flows (SAF-n) over the slope at depths between 1000 and $3500 \mathrm{~m}$ based on the data of sections in January 2010 and over the depths of $3500 \mathrm{~m}$ based on the data in November 2011. The next jet (SAF-5) may occupy either a remote or close location to the SAF-n jet (Figure 1). 


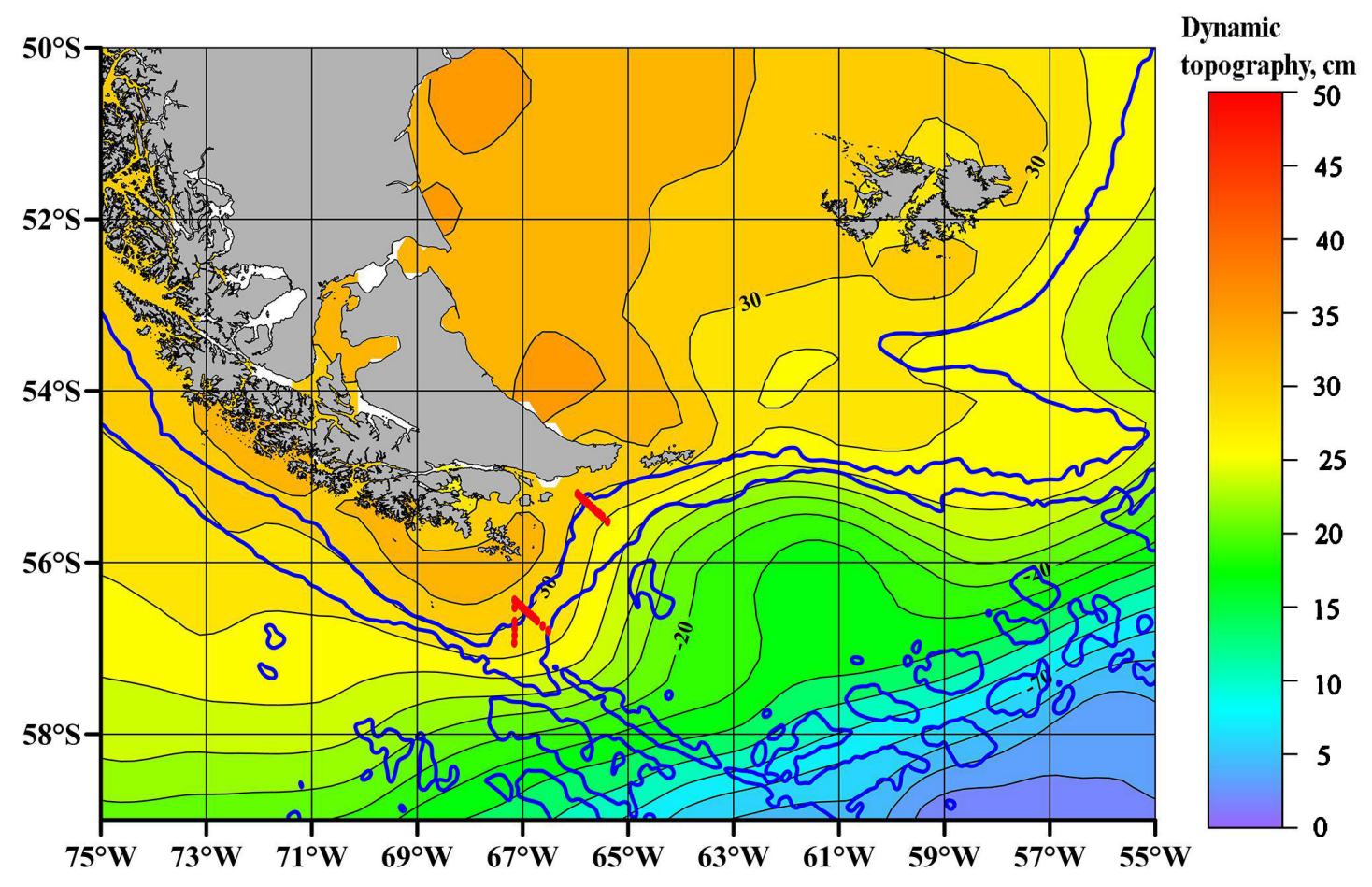

Figure 2. Absolute dynamical topography of the region based on satellite altimetry averaged over 26 years of observations (black lines and color scale). Isobaths 1000, $3500 \mathrm{~m}$ are shown with blue lines. Red dots indicate CTD/LADCP casts.

\section{Data Analysis}

In this paper the structure of the costal jet is studied over three lines across the continental slope of Tierra del Fuego in the Drake Passage during cruise 79 of the R/V Akademik Mstislav Keldysh. The location of these lines is shown in Figure 2.

Four sections using the shipborne SADCP profiler $(75 \mathrm{kHz})$ were occupied in cruise 79 of the $\mathrm{R} / \mathrm{V}$ Akademik Mstislav Keldysh approximately normal to the isobaths of the continental slope of Tierra del Fuego in the Drake Passage. The northern section in Figure 2 was repeated twice.

Measurements of temperature, conductivity, and depth were performed at each hydrographic station using the CTD SBE 911 (the southwestern section 1) or SBE 19 plus (sections 2 middle and 3 northern) instruments. Current velocities were measured by a Lowered Acoustic Doppler Current Profiler (LADCP, RDI Monitor, $300 \mathrm{kHz}$ ) over sections 1 and 2. The profiler was mounted together with the CTD on the SBE 32 Carousel Water Sampler. The measurements were carried out to the depths of $3-7 \mathrm{~m}$ above the bottom. Location of stations on the chart of bathymetry and absolute dynamical topography is shown in Figure 2 .

The shallowest station of the sections in 2010 and 2011 were located over depths of 500-1000 m. In 2020 the sections stopped over a depth of 120 $130 \mathrm{~m}$ and the distance between stations was 2 nautical miles. This is much smaller than in the previous years. Such location of stations allowed us to reveal one more coastal jet over the slope in a high resolution data. Two LADCP sections are shown in the figures below (Figure 3 and Figure 4). The width of this coastal jet above the shelf break is about $15-20 \mathrm{~km}$. Its core is approximately over the $400-600 \mathrm{~m}$ isobath. It penetrates to the depths of $200-250 \mathrm{~m}$. Another core of the coastal jet is located at a distance of about $30 \mathrm{~km}$ front the one over the shelf break. The jet follows the direction of isobaths. Velocities in the jet reach $40 \mathrm{~cm} / \mathrm{s}$. It is likely that this jet is a local one and does not continue along the entire circle around Antarctica.

The coastal jet is located near the slope over depths of $500-600 \mathrm{~m}$. The SAC-n jet is located approximately at a distance of $200 \mathrm{~km}$ from the coastal jet. 


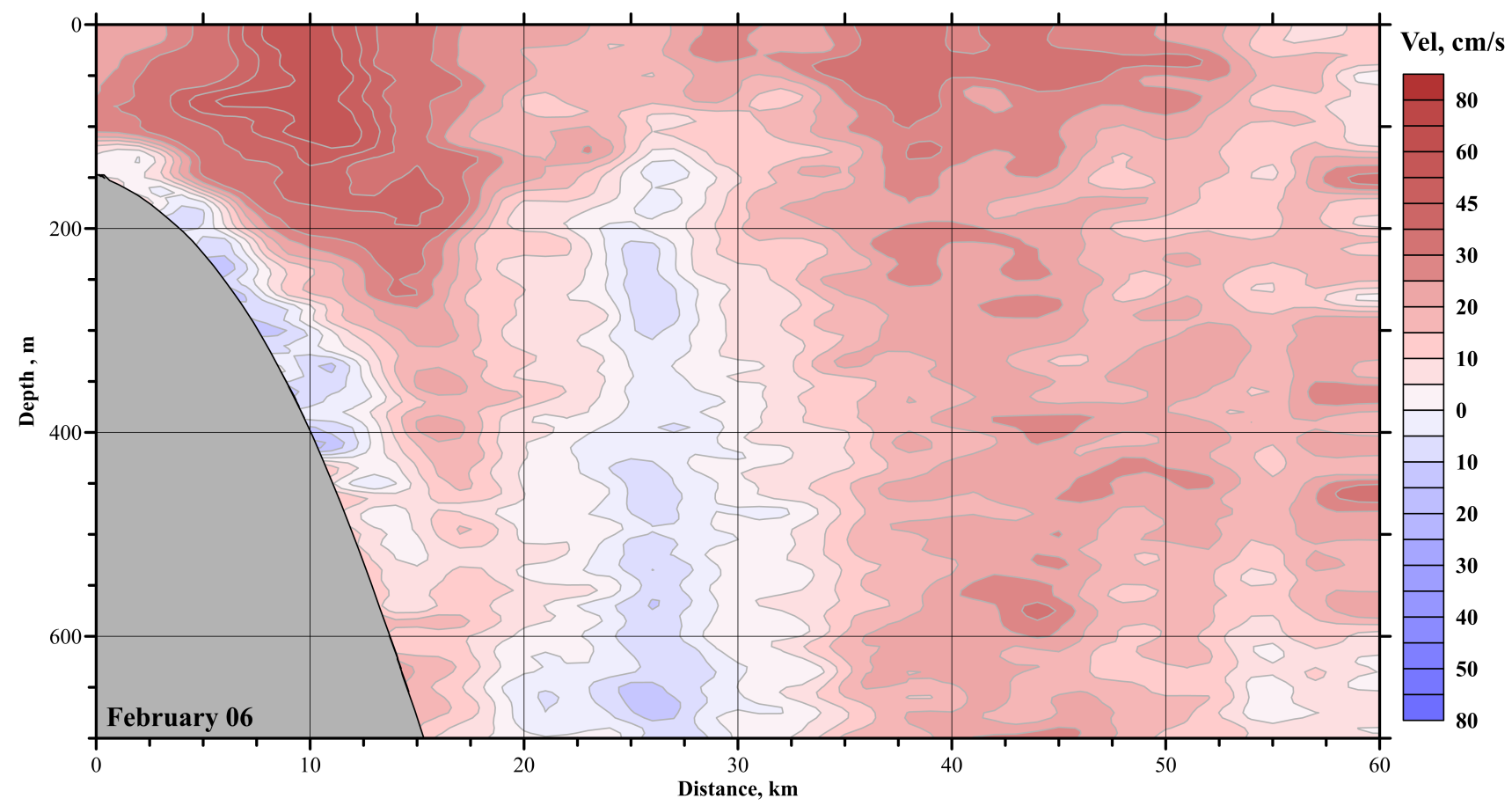

Figure 3. Velocity section across the coastal jets on 6 February. Positive direction to the east.

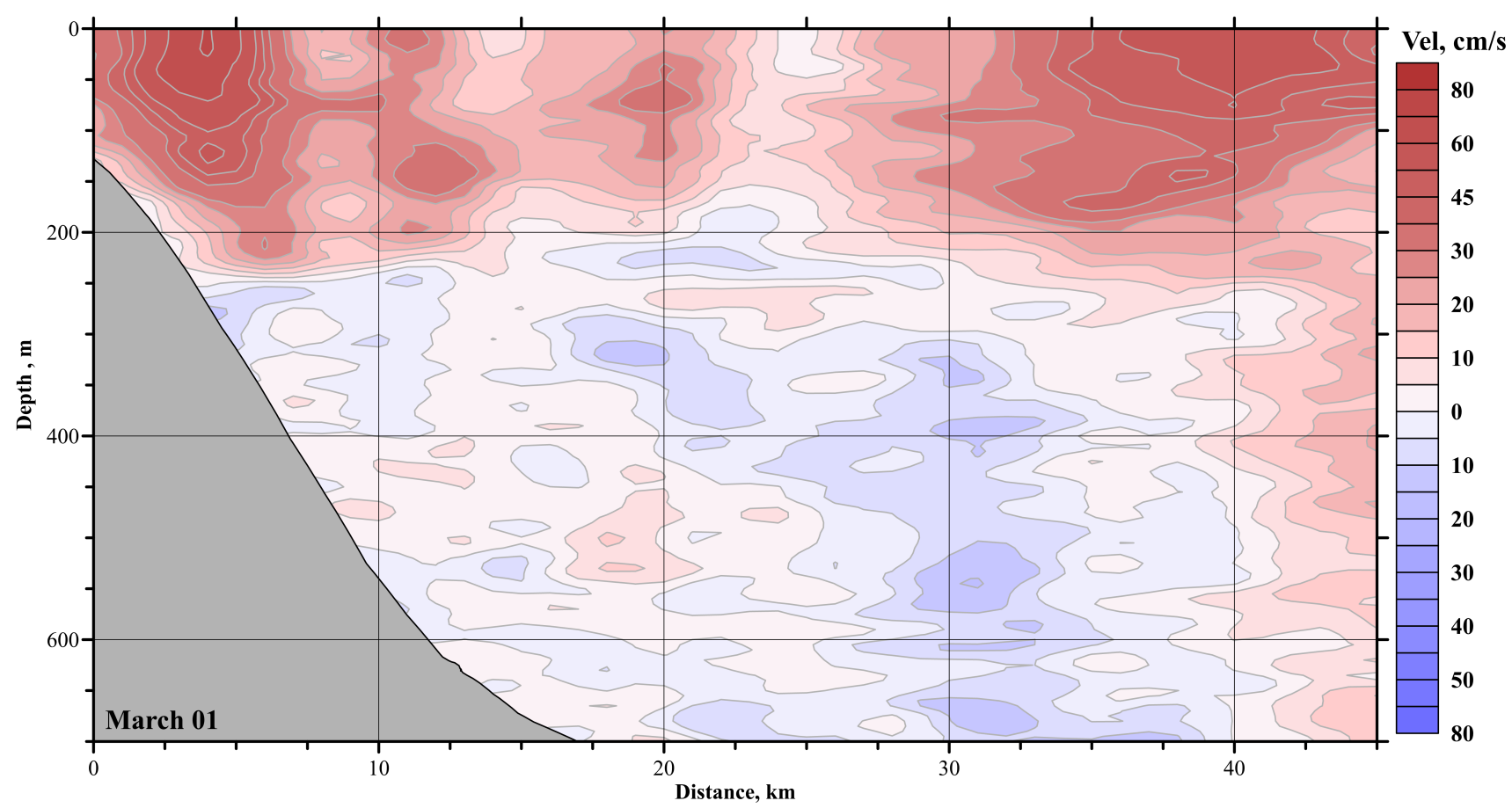

Figure 4. Velocity section across the coastal jets on 1 March. Positive direction to the east. 


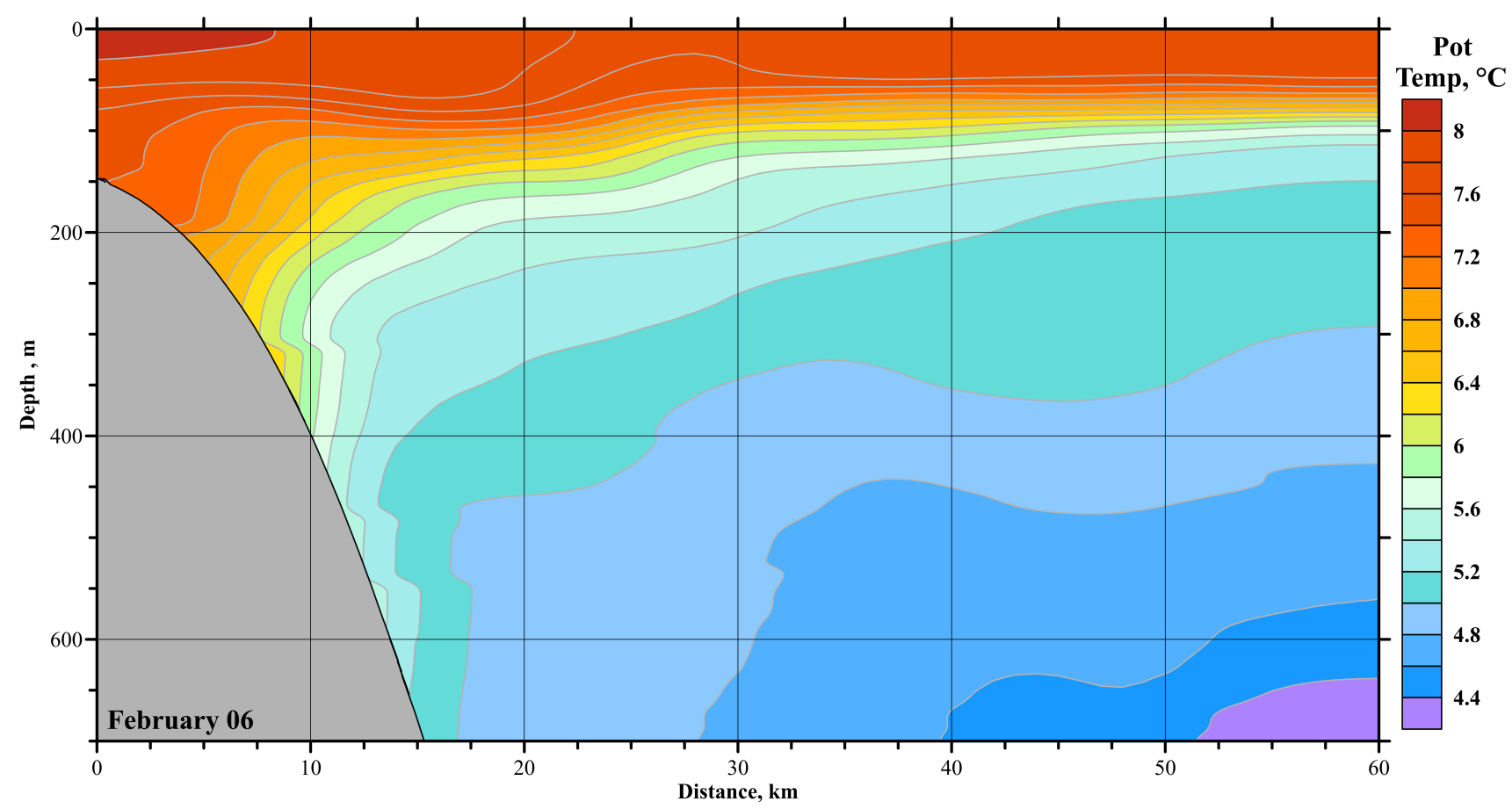

Figure 5. Potential temperature section across the coastal jets on 6 February.

The temperature section over the section in 6 February is shown in Figure 5. Isotherms are strongly inclined to the continental slope. The potential temperature at a depth of $400 \mathrm{~m}$ is approximately $5.12^{\circ} \mathrm{C}$.

Judging from the chart of the absolute dynamical topography (ADT) and locations of stations the coastal jet corresponds to the ADT values smaller than $30 \mathrm{~cm}$. The contour lines of ADT smaller than $30 \mathrm{~cm}$ continue into the shallow region between Tierra del Fuego and Falkland Islands. Then the jet that corresponds to these ADT values can initiate the Patagonian Current. The next jet (SAF-n with ADT values exceeding $30 \mathrm{~cm}$ ) that follows the depths exceeding $1000 \mathrm{~m}$ continues south of the Burdwood Bank. This jet participates in the formation of water structure in the South Atlantic [Frey et al., 2019].

\section{Conclusions}

The extreme northern jet of the Antarctic Circumpolar Current is studied based on the measurements in cruise 79 of the $\mathrm{R} / \mathrm{V}$ Akademik Mstislav Keldysh to the region of the Drake Passage in February-March 2020. The jet occupies a posi- tion over the slope of Tierra del Fuego Island over a depth range of $400-600 \mathrm{~m}$. The width of this coastal jet is about $15-20 \mathrm{~km}$. It penetrates to the depths of 200-300 m. Velocities in the jet reach $40 \mathrm{~cm} / \mathrm{s}$. This is a local jet and does not continue along the entire circle around Antarctica.

Acknowledgments. This research was performed in the framework of the state assignment of Russia (theme No. 0128-2019-0008). The work was supported by the Russian Science Foundation (grant no. 16-17-10149).

\section{References}

Berloff, P., I. Kamenkovich, J. Pedlosky (2009), A model of multiple zonal jets in the oceans: dynamical and kinematical analysis, J. Phys. Oceanogr., 39, No. 11, 2711-2734, Crossref

Burkov, V. A. (1994), Antarctic jets, Oceanology, 34, No. 2, 169-177.

Deacon, G. E. R. (1937), The hydrology of the Southern Ocean, Discov. Rep., 15, 1-124.

Frey, D. I., E. G. Morozov, I. Ansorge, et al. (2019), Thermohaline structure of Antarctic Bottom Water in the abyssal basins of the South Atlantic, Russian Journal of Earth Sciences, 19, ES5005, Crossref

Killworth, P. D., C. W. Hughes (2002), The Antarctic Circumpolar Current as a free equivalent 
barotropic jets, J. Mar. Res., 60, No. 1, 19-45, Tarakanov, R. Yu. (2012), The Scotia Sea and Crossref the Drake Passage as an orographic barrier for the

Kort, V. G. (1959), New data on Antarctic water transport, Bull. Sov. Antarctic Expedition, No. 9, 24-29. (in Russian)

Koshlyakov, M. N., S. V. Gladyshev, et al. (2011), Currents in the Western Drake Passage according to the observations in January of 2010, Oceanology, 51, 187-198, Crossref

Koshlyakov, M. N., S. V. Gladyshev, et al. (2013), Currents in the Drake Passage by the observations in October-November of 2011, Oceanology, 53, 1-12, Crossref

Orsi, A. H., Th. Whitworth, III, W. D. Nowlin, Jr. (1995), On the meridional extent and fronts of the Antarctic Circumpolar Current, Deep-Sea Res., 42, No. 5, 641-673, Crossref

Sokolov, S., S. R. Rintoul (2009), The circumpolar structure and distribution of the Antarctic Circumpolar Current fronts. Part A: Mean circumpolar paths, J. Geophys. Res., 114, C11018, Crossref Antarctic Circumpolar Current, Oceanology, 52, 157170, Crossref

Tarakanov, R. Yu., A. M. Gritsenko (2014a), The frontal and jet structure south of Africa based on the data of SR02 transect in December of 2009, Oceanology, 54, 401-413, Crossref

Tarakanov, R. Yu., A. M. Gritsenko (2014b), Finejet structure of the Antarctic Circumpolar Current south of Africa, Oceanology, 54, 677-687, Crossref

Tarakanov, R. Yu., A. M. Gritsenko (2018), Jets of the Antarctic Circumpolar Current in the Drake Passage based on hydrographic section data, Oceanology, 58, 503-516, Crossref

\section{Corresponding author:}

E. G. Morozov, Shirshov Institute of Oceanology RAS, 36 Nakhimovsky Prospect, 117997 Moscow. (egmorozov@mail.ru) 